\title{
Persistent idiopathic hypoglossal nerve palsy: A motor neuron disease-mimic syndrome?
}

\author{
ANTONIO ILARDI, CRISTINA MOGLIA, STEFANIA CAMMAROSANO, \\ ANTONIO CANOSA, DAVIDE BERTUZZO, UMBERTO MANERA, GIUSEPPE FUDA, \\ ADRIANO CHIÒ \& ANDREA CALVO
}

ALS Centre, 'Rita Levi Montalcini' Department of Neuroscience, University of Torino, Torino, Italy

\section{Introduction}

Unilateral isolated hypoglossal nerve palsy (IHNP) is a condition (1-7) usually symptomatic of a pathology of the skull base $(6,8)$. In rare cases, IHNP remains of unknown aetiology and is classified as idiopathic IHNP; its course is usually benign with a spontaneous remission $(1,6)$. To our knowledge, only very few cases of persistent, idiopathic IHNP have been described $(1,4,5,9,10)$. We report the case of a young patient with a persistent idiopathic IHNP, along with a brief review of the literature.

\section{Case report}

A 17-years-old male presented to our clinic with mild dysarthria and left deviation of the tongue when protruded (Figure 1). He reported the onset of slight difficulty in speech two years earlier. His medical history was unremarkable, without a family history for neurological diseases. Neurological examination showed fasciculations and hypotrophy on the left side of the tongue and mild dysarthria, without dysphagia; no other clinical signs were observed. The patient underwent the following laboratory tests: full blood cells count, glucose, serum electrolytes, renal, liver and thyroid function test, creatine kinase, serum electrophoresis, inflammatory markers, vitamin B12, folate, iron, ferritin, transferrin and autoimmunity tests, all of which were unremarkable. AngiotensinConverting Enzyme blood level was normal. Virologic serology (HIV, CMV, EBV, HSV 1-2) and serology for Borrelia burdorgferi were negative. Cerebrospinal fluid examination was normal. An otorhinolaryngological evaluation revealed isolated hypotrophy of the left side of the tongue; moreover,

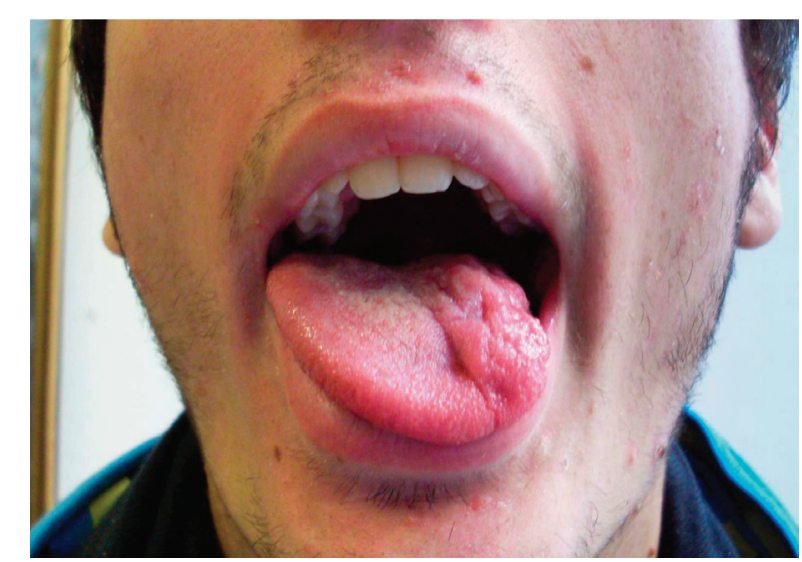

Figure 1. Unilateral hypoglossal nerve palsy. Patient presented left side hypotrophy and deviation of the tongue when protruded.

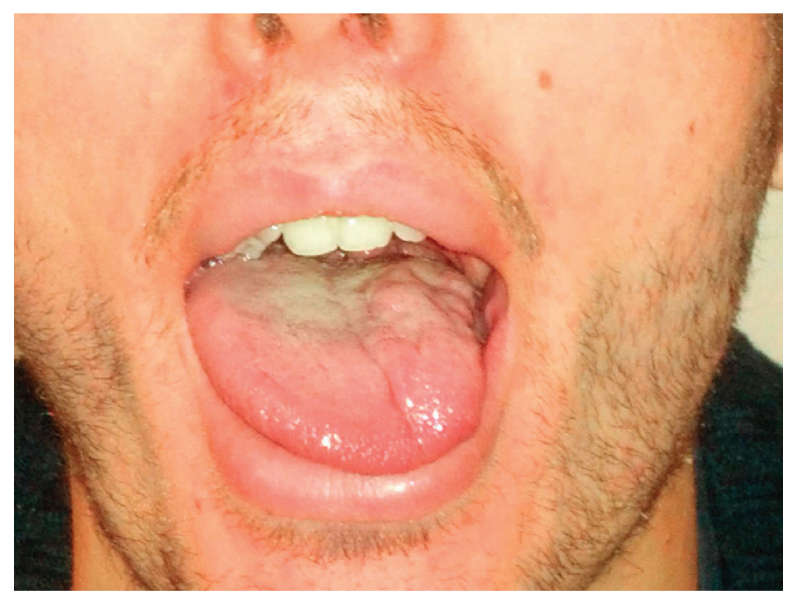

Figure 2. Unilateral hypoglossal nerve palsy. After 30 months of follow-up the patient's neurological examination remained unchanged. 
Table I. Cases of persistent IHNP.

\begin{tabular}{lccc}
\hline Authors & Age at onset (years)/gender & Duration of symptoms & Outcome \\
\hline Omura et al., 1997 & $60 / \mathrm{F}$ & 3 months & Unchanged after two years of follow-up \\
Begán-Sebastián et al., 1998 & $24 / \mathrm{F}$ & 10 years & Unchanged after 12 months of follow-up \\
Do an and Erdal, 2003 & $42 / \mathrm{F}$ & 23 years & Unchanged after six months follow-up \\
Ho et al., 2004 & $25 / \mathrm{F}$ & 5 years & Unchanged after four years of follow-up \\
Freedman et al., 2008 & $22 / \mathrm{M}$ & 18 months & Unchanged after 12 months of follow-up \\
Present case & $17 / \mathrm{M}$ & 24 months & Unchanged after 30 months of follow-up \\
\hline
\end{tabular}

a fibroendoscopy evaluation of swallowing was normal. Electromyography (EMG) of the tongue showed signs of active denervation (fibrillations) and chronic neurogenic signs (recruitment reduction), while needle EMG and nerve conduction velocities at the four limbs were normal. Magnetic resonance imaging of the brain and cervical spine were negative; magnetic resonance angiography of neck and intracranial arteries showed no abnormalities. After a 30-month follow-up period, the patient's neurological examination remained unchanged (Figure 2). The EMG of the tongue was repeated: it showed persistent but less florid signs of active denervation (positive sharp waves) and chronic neurogenic signs (increased MUAP amplitude and duration, recruitment reduction).

Written informed consent was obtained from the patient for publication of this case report and any accompanying images.

\section{Discussion}

Unilateral IHNP is an uncommon finding because of hypoglossal motor nucleus and fibres proximity to other neurological structures; for this reason hypoglossal nerve palsy usually develops in association with other neurological signs and symptoms $(1,6,7)$. IHNP has previously been reported by several authors (1-7); it is usually referred as symptomatic of pathology of the base of the skull $(6,8)$. Hypoglossal nerve palsy may also occur as a consequence of head and neck injury $(7,9)$, congenital or acquired vascular abnormalities and viral infections such as infectious mononucleosis $(3,6)$, which may cause a self-limiting form of IHNP. Other causes of IHNP include motor neuron disease, neck surgery, carotid endoarterectomy, dural arteriovenous fistula of the transverse sinus, thrombosis of median branches of the vertebral artery, Arnold-Chiari malformation, syringobulbia, cervical osteophytosis, sarcoidosis, diabetes mellitus, autoimmune disease, vasculitis, multiple sclerosis, Schwannoma of the hypoglossal nerve, and Guillain-Barré syndrome. $(2,5,6,8,9)$.

Idiopathic IHNP - i.e. of unknown aetiology - is a rarer finding. It has usually a benign course and the majority of patients have an excellent outcome (6). In addiction to these transient forms, persistent idiopathic IHNP has already been described in very few cases: a Medline search revealed only five cases of persistent IHNP (Table I).
In our case, the aetiology of hypoglossal nerve palsy could not be determined by thorough investigations. The patient's medical history excluded trauma or surgical procedures near the neck, while laboratory tests were negative for infectious agents, autoimmune diseases and other medical conditions. Neuroimaging studies showed no signs of a lesion growing near the skull base or a malformative disease; similarly, vascular abnormalities were ruled out. Moreover, the lack of motor neuron impairment in the cervical, thoracic and lumbar districts and the absence of clinical progression over several months excluded the diagnosis of motor neuron disease. In the absence of any underlying pathological condition, the patient was diagnosed as having a persistent idiopathic form of IHNP. A follow-up of the patient is still ongoing.

\section{Conclusions}

IHNP may be caused by different pathologies. It is of utmost importance to rule out a malignant disease or to identify a treatable condition, such as spontaneous or traumatic vascular abnormalities. It is also important to rule out a diagnosis of motor neuron disease.

\section{Acknowledgements}

This study received grants from the Italian Ministry of Health and European Community's Health Seventh Framework Programme.

Declaration of interest: The authors report no conflicts of interest. The authors alone are responsible for the content and writing of the paper.

\section{References}

1. Freedman M, Jayasundara H, Stassen LFA. Idiopathic isolated unilateral hypoglossal nerve palsy: a diagnosis of exclusion. Oral Surg Oral Med Oral Pathol Oral Radiol Endod. 2008;106:e22-6.

2. Patron V, Roudaut P-Y, Lerat J, Vivent M, Bessède JP, Aubry $\mathrm{K}$. Isolated hypoglossal palsy due to cervical osteophyte. Eur Ann Otorhinolaryngol Head Neck Dis. 2012;129:44-6.

3. de Simone PA, Snyder D. Hypoglossal nerve palsy in infectious mononucleosis. Neurology. 1978;28:844-7.

4. Begán-Sebastián JV, Milián-Masanet MA, PeñarrochaDiago M, Lloria de Miguel. Persistent Idiopathic Unilateral Hypoglossal Nerve Palsy. J Oral Maxillofac Surg. 1998;56: 507-10. 
5. Ho MSW, Fardy MJ, Crean JV. Persistent idiopathic unilateral isolated hypoglossal nerve palsy: a case report. British Dental Journal. 2004;196:205-7.

6. Combarros O, Alvarez de Arcaya A, Berciano J. Isolated unilateral hypoglossal nerve palsy: nine cases. J Neurol. 1998; 245:98-100.

7. Boban M, BrinarVV, Habek M, Rados M. Isolated Hypoglossal Nerve Palsy: A Diagnostic Challenge. Eur Neurol. 2007; 58:177-81.
8. Keane JR. Twelfth-Nerve Palsy. Analysis of 100 cases. Arch Neurol. 1996;53:561-6.

9. Omura S, Nakajima Y, Kobayashi S, Ono S, Fujita K. Oral manifestations and differential diagnosis of isolated hypoglossal nerve palsy: report of two cases. Oral Surg Oral Med Oral PatholOral Radiol Endod. 1997;84:635-40.

10. Doğan $M$, Erdal O. Isolated unilateral hypoglossal nerve paralysis: a report of two cases (in Turkish). Kulak Burun Bogaz Ihtis Derg. 2003;11:125-8. 